\title{
Preparation and characterization of PVDF flat-sheet membranes for direct contact membrane distillation
}

\author{
Deyin Hou ${ }^{\mathrm{a}, *}$, Hua Fan ${ }^{\mathrm{b}}$, Qinliang Jiang ${ }^{\mathrm{b}}$, Jun Wang ${ }^{\mathrm{a}, *}$, Xiaohui Zhang ${ }^{\mathrm{a}, \mathrm{c}}$ \\ ${ }^{a}$ State Key Laboratory of Environmental Aquatic Chemistry, Research Center for Eco-Environmental Sciences, Chinese Academy of Sciences, Beijing 100085, PR China \\ ${ }^{\mathrm{b}}$ School of Environmental and Chemical Engineering, Nanchang University, Jiangxi 330031, PR China \\ ${ }^{\mathrm{c}}$ Department of Food and Environmental Technology, Beijing Vocational College of Electronic Science, Beijing 100029, PR China
}

\section{A R T I C L E I N F O}

Article history:

Received 29 May 2014

Received in revised form 23 August 2014

Accepted 26 August 2014

Available online 3 September 2014

\section{Keywords:}

Membrane distillation

Polyvinylidene fluoride

Flat-sheet membrane

Desalination

Hydrophobicity

\begin{abstract}
A B S T R A C T
The polyvinylidene fluoride (PVDF) flat-sheet membranes for direct contact membrane distillation (DCMD) were prepared through coating and wet phase inversion process. The effects of solvent, polymer concentration, non-solvent additive and nonwoven fabric on membrane morphology, porosity, pore size, pore size distribution, hydrophobicity and permeability were investigated. It was found that the membrane using N,N-dimethylacetamide as solvent obtained good permeability, and the polymer dope containing 20 wt.\% PVDF was the most suitable for hydrophobic flat-sheet membrane preparation. The PVDF flat-sheet membranes with different non-solvent additive such as acetone, phosphoric acid, glycerine, $\mathrm{LiCl}$ and PEG 400 were prepared and the membrane using $5 \mathrm{wt} . \%$ acetone and $3 \mathrm{wt} . \% \mathrm{H}_{3} \mathrm{PO}_{4}$ as mixed additive had the highest permeate flux. The nonwoven fabric could prevent membrane shrinkage, while both pore size and permeate flux of the PVDF/nonwoven fabric composite membrane were enhanced. Although the nonwoven fabric caused the membrane surface roughness decline, the contact angle only decreased slightly. The PVDF/nonwoven fabric composite membrane exhibited satisfying performance stability during the $240 \mathrm{~h}$ continuous desalination experiments, indicating that the resultant flat-sheet membrane may be of great potential to be utilized in DCMD process for desalination.
\end{abstract}

(c) 2014 Elsevier B.V. All rights reserved.

\section{Introduction}

Membrane distillation (MD) is a membrane separation technology usually applied to treat salt solutions and the permeate flux of MD is driven by a vapor pressure difference resulted from the temperature difference across a hydrophobic membrane [1]. Although the porous membrane serves as a physical barrier between hot feed and cold permeate, it plays a crucial role during MD process [2]. The membrane designed for MD process should be hydrophobic to prevent the aqueous solution from entering into its dry pores until the operating pressure exceeds the liquid entry pressure of water (i.e., $L E P w$ ) [3]. Since the hot feed to be treated must be in direct contact with one side of the membrane, a desirable thermal stability and chemical resistance to feed solution are necessary for the membrane. Besides, other membrane properties, such as thickness, porosity, pore size and pore size distribution can also influence membrane performance [4-6].

The membranes used in MD are mainly made of hydrophobic materials such as polypropylene (PP), polytetrafluoroethylene

\footnotetext{
* Corresponding authors. Tel./fax: +86 1062849150.

E-mail addresses: dyhou@rcees.ac.cn, deyinhou@126.com (D. Hou), junwang@rcees.ac.cn (J. Wang).
}

(PTFE) and polyvinylidene fluoride (PVDF) [7]. The PP membrane can be prepared by thermally induced phase separation (TIPS) process or melt-spinning and cold-stretching (MSCS) method [8]. PTFE membrane is usually formed through stretching and heating process [9]. Among these three materials, only PVDF can be prepared by non-solvent induced phase separation (NIPS) method and form asymmetric membrane morphology, which is important for achieving a good permeability $[10,11]$. Most membranes used for MD so far are originally marketed for microfiltration or ultrafiltration process and these commercial membranes are incompletely adequate for MD because of weak hydrophobicity, poor permeability, low solute rejection, and so on.

In recent years, more attention has been put into preparing hydrophobic membranes, particularly the PVDF membrane specifically for MD process. Tomaszewska [12] fabricated hydrophobic PVDF flat-sheet membrane for MD by using $\mathrm{LiCl}$ as additive and the effect of the $\mathrm{LiCl}$ concentration in casting solution on permeate flux was studied. Fan et al. [13] prepared hydrophobic PVDF symmetric flat-sheet membranes for vacuum membrane distillation (VMD) by the vapor-induced phase separation method using double-layer casting process, Feng et al. [14,15] fabricated flat-sheet membranes from poly(vinylidene fluoride-co-tetrafluoro- 
ethylene) and poly(vinylidene fluoride-co-hexafluoro propylene). Wang et al. [16] prepared PVDF asymmetric hollow fiber membranes by introducing small molecular additives such as water, ethanol and 1-propanol, and found that the spun PVDF membranes exhibited good mechanical strength and excellent hydrophobicity. Yeow et al. [17] and Wang et al. [18] fabricated PVDF hollow fiber membranes via phase inversion method using lithium perchlorate $\left(\mathrm{LiClO}_{4}\right)$ and ethylene glycol (EG) as the additive, respectively. Simone et al. [19] prepared microporous hydrophobic PVDF hollow fibers for VMD by using water and poly(vinyl pyrrolidone) (PVP) as pore forming additives, and the flux can reach as high as $18 \mathrm{~kg} /$ $\mathrm{m}^{2} \mathrm{~h}$ at $50{ }^{\circ} \mathrm{C}$ under $20 \mathrm{mbar}$ vacuum pressure. Teoh and Chung [20] fabricated PVDF-PTFE hollow fibers showing improved hydrophobicity and macrovoid free structure. Chung et al. [21,22] developed multichannel rectangular membranes with grooved outer selective surface and fabricated novel lotus-root-like multi-bore PVDF hollow fiber membrane. Khayet presented the concept of hydrophilic/hydrophobic composite membrane firstly and prepared a series of novel composite MD flat-sheet membranes by phase inversion method in a single casting step [23-28]. Edwie and Chung [29] used the co-extrusion method to fabricate PVDF-Polyacrylonitrile dual layer hydrophilic/hydrophobic hollow fiber membranes, and a flux of $14 \mathrm{~kg} / \mathrm{m}^{2} \mathrm{~h}$ was achieved with the feed temperature at $60^{\circ} \mathrm{C}$.

Although hollow fiber membranes have higher packing density and are believed to be more economical than flat-sheet membranes [30], the latter own higher mass transfer coefficient and better antifouling properties compared with hollow fiber membranes. As for the flat-sheet membrane with a support layer, it presents stronger mechanical strength and can withstand intense hydraulic impact and flow disturbance, which is very important from an industrial application standpoint.

The present investigation was carried out to prepare PVDF flatsheet membranes for direct contact membrane distillation (DCMD) by coating and wet phase inversion process. The influences of some important factors such as polymer concentration, solvent and nonsolvent additive, nonwoven fabric support on the flat-sheet membrane structure and properties were analyzed comprehensively. The membranes prepared in this study were characterized by their hydrophobicity, porosity, pore size and pore size distribution. MD experiments were carried out using a DCMD configuration and sodium chloride solution was employed as the feed. The dependences of the DCMD flux and salt rejection on the properties of the prepared membrane were also discussed and evaluated.

\section{Materials and methods}

\subsection{Materials}

PVDF(FR-904) was obtained from Shanghai 3F new materials Co., Ltd. (China), its molecular weight (Mw) is about $1.02 \times 10^{6} \mathrm{~g} / \mathrm{mol}$. N,N-dimethylformamide (DMF, >99\%), N,N-dimethylacetamide
(DMAc, >99\%), Dimethyl sulfoxide (DMSo, >99\%), and N-methyl-2pyrrolidone (NMP, >99\%) were employed as the solvent, all these purchased from Shanghai Jingwei Chemical Co., Ltd. (China). Phosphoric acid (AR grade, $>85.0 \%$ ), acetone (AR grade, $>99.5 \%$ ), were supplied by Sinopharm Chemical Reagent Co., Ltd. (China). Glycerine (AR grade, >99.5\%), $\mathrm{LiCl}$ (GR grade, $>95.0 \%$ ) and polyethylene glycol (PEG, Mw $=400,>99.5 \%$ ) were supported by Tianjin Guangfu Research Institute of Fine Chemical Engineering (China). Ethanol (GR grade, 99.9\%) and $\mathrm{NaCl}$ (99.5\%) were from Beijing Chemical works (China). The ultrapure water used in all experiments was produced by a Milli-Q BIOCEL unit (MilliPore, USA) with the resistivity of $18 \mathrm{M} \Omega \mathrm{cm}$.

\subsection{Membrane preparation}

The PVDF powder was dried at $100{ }^{\circ} \mathrm{C}$ under vacuum for $24 \mathrm{~h}$ to remove its moisture content before dope preparation. A desirable amount of dried PVDF powder was weighed and poured into a organic solvent with non-solvent additive, then the polymer dope was stirred continuously for about $48 \mathrm{~h}$ at $50{ }^{\circ} \mathrm{C}$ in order to ensure its homogeneity. Afterwards, the stirring was stopped and the gas bubbles in the dope were released at $50{ }^{\circ} \mathrm{C}$ for at least $72 \mathrm{~h}$.

The degassed dope solution was coated on a glass plate or on a polyester nonwoven fabric at room temperature with a knife gap of $0.2 \mathrm{~mm}$. After being exposed $30 \mathrm{~s}$ in air, the cast film was immersed immediately into coagulation bath. The precipitated membrane was taken out of the coagulation bath and rinsed with running water to remove the residual solvent and non-solvent additive. At last, the wetting membrane was dried in air at room temperature until a dry flat-sheet porous membrane was achieved.

\subsection{Membrane morphology study}

The surface layer morphology of flat-sheet membrane was investigated with a HITACHI S-3000N scanning electron microscope (SEM) (Hitachi Ltd., Japan). Membrane samples were frozen in liquid nitrogen, fractured to obtain fragments, and sputtered with gold using a HITACHI E-1010 Ion Sputtering device for SEM observation.

\subsection{Membrane surface analysis}

The membrane hydrophobicity was determined by gauges of contact angle of droplet with the OCA20 Video-Based Contact Angle Meter (DataPhysics Instruments Ltd., Germany). Water droplets of about $0.5 \mu \mathrm{L}$ were carefully dropped onto the flat-sheet membrane skin through a syringe under ambient temperature and the contact angles were obtained by measuring five different positions of each sample.

An atomic force microscope (AFM) (NanoScope IIIa, Digital Instruments, USA) was employed to analyze the membrane surface roughness. All membrane samples were measured by using a same

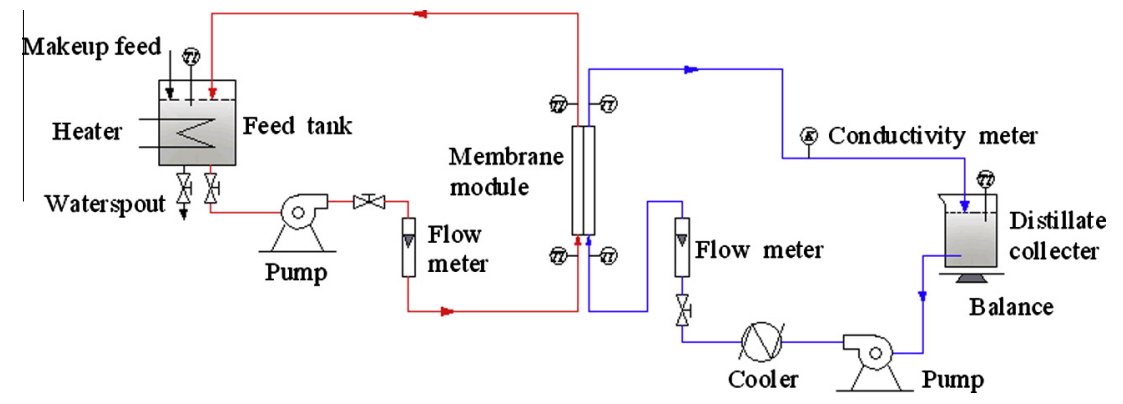

Fig. 1. Schematic diagram of the experimental DCMD set-up. 

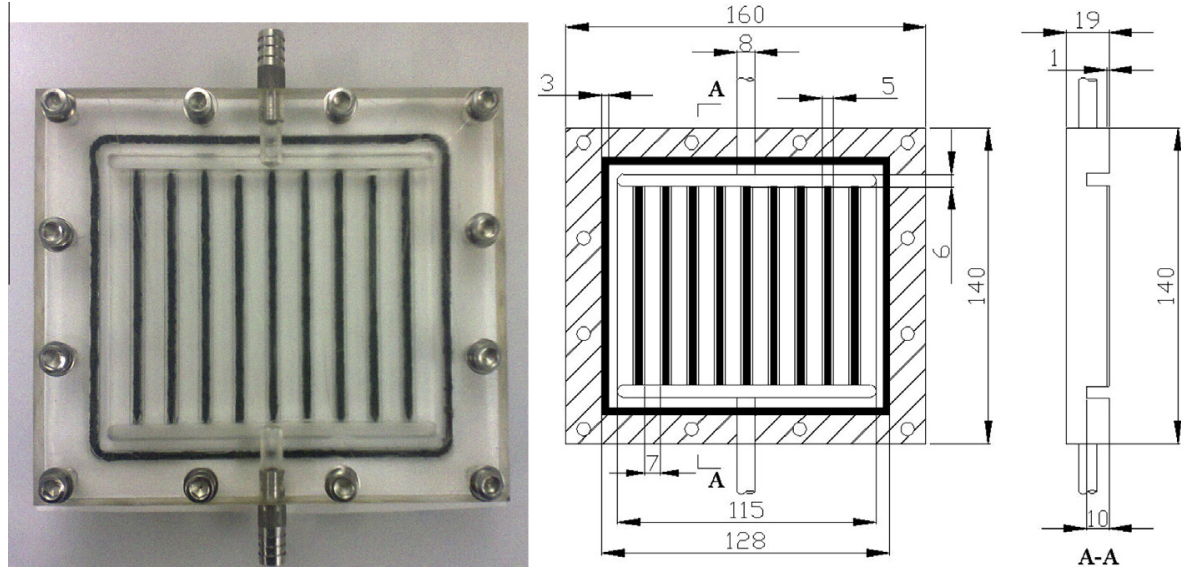

Fig. 2. Photograph and structure drawing of the flat-sheet membrane module.
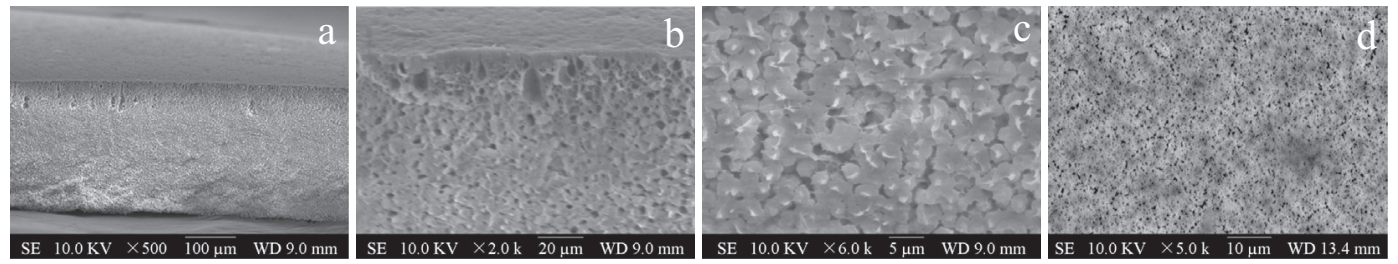

$\mathrm{DMF}$
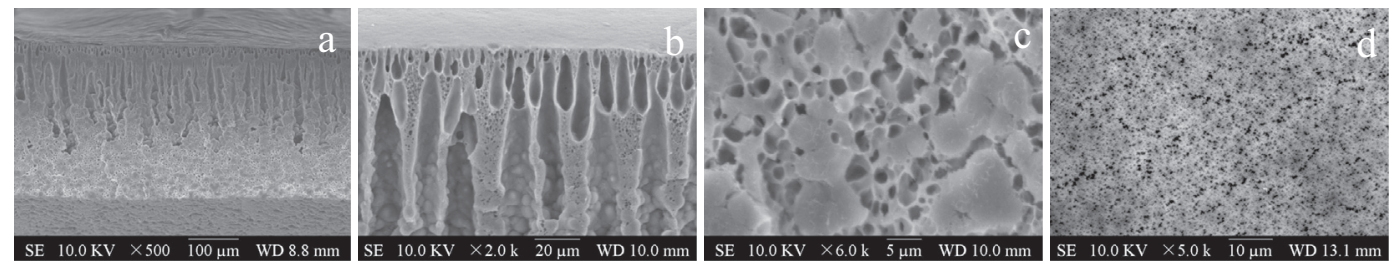

DMAc
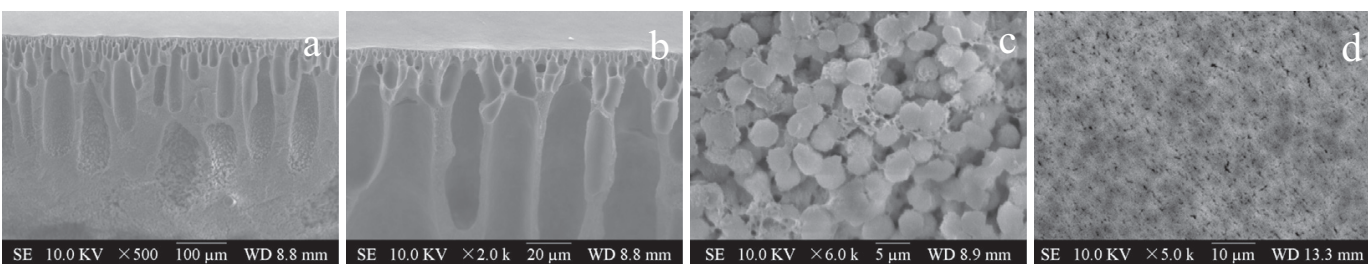

DMSo
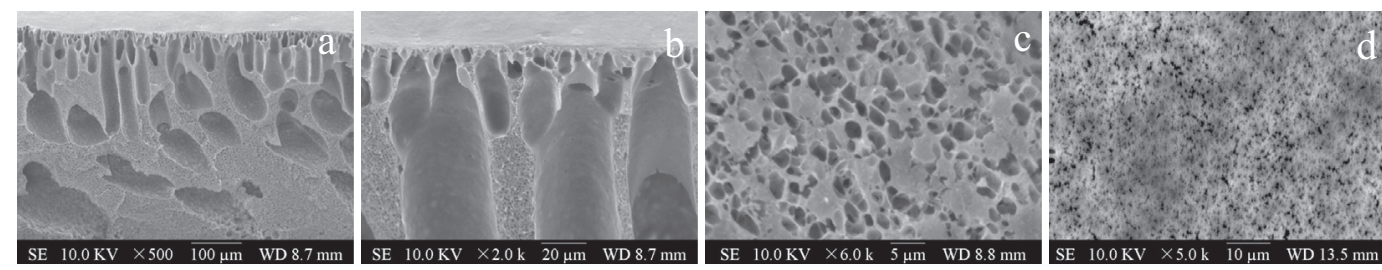

NMP

Fig. 3. SEM images of PVDF flat-sheet membranes cast from different solvent (a) overall cross section, (b) enlarged cross section near membrane surface, (c) sponge-like layer and (d) membrane surface.

Table 1

Properties of PVDF flat-sheet membranes cast from different solvents.

\begin{tabular}{|c|c|c|c|c|c|}
\hline Solvent & Porosity (\%) & Thickness $(\mu \mathrm{m})$ & Contact angle $\left(^{\circ}\right)$ & Mean pore size $\left(\times 10^{-2} \mu \mathrm{m}\right)$ & Flux $\left(\mathrm{kg} / \mathrm{m}^{2} \mathrm{~h}\right)$ \\
\hline DMF & $37.93 \pm 0.6$ & $104.2 \pm 3.5$ & $84.3 \pm 0.7$ & 4.50 & 1.63 \\
\hline DMAC & $41.50 \pm 2.3$ & $138.1 \pm 2.1$ & $76.1 \pm 1.5$ & 4.75 & 1.85 \\
\hline DMSo & $48.82 \pm 3.2$ & $164.9 \pm 1.3$ & $78.5 \pm 0.8$ & 3.86 & 2.18 \\
\hline NMP & $52.75 \pm 1.5$ & $169.3 \pm 0.6$ & $70.7 \pm 1.2$ & 5.12 & 2.40 \\
\hline
\end{tabular}



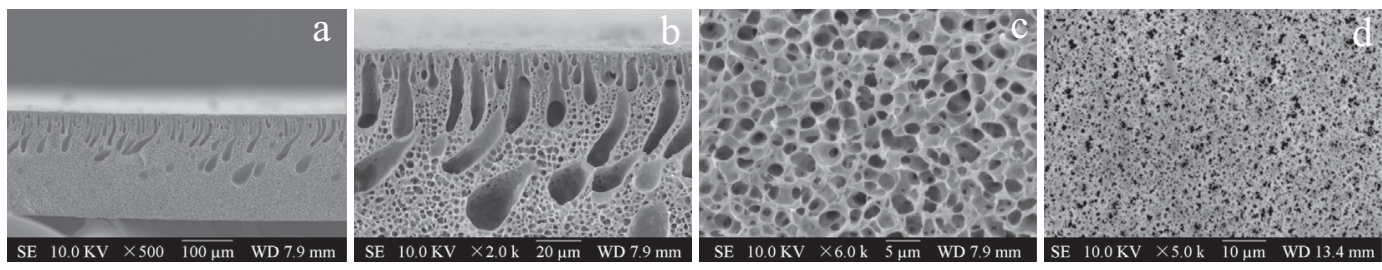

10 wt. $\%$
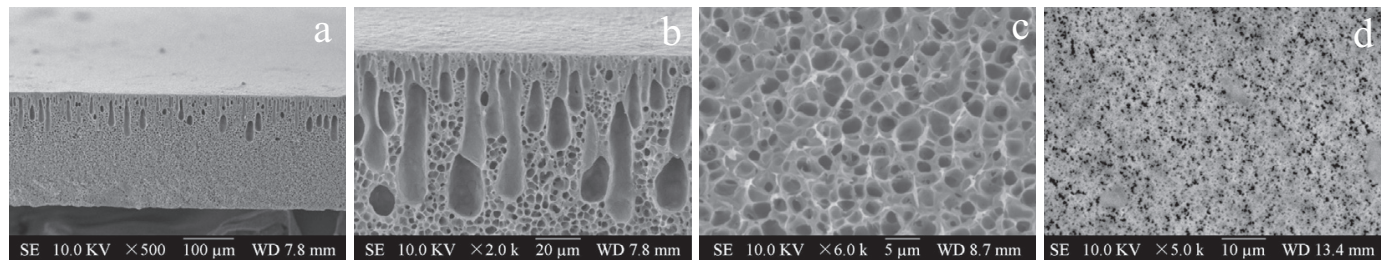

15 wt. $\%$
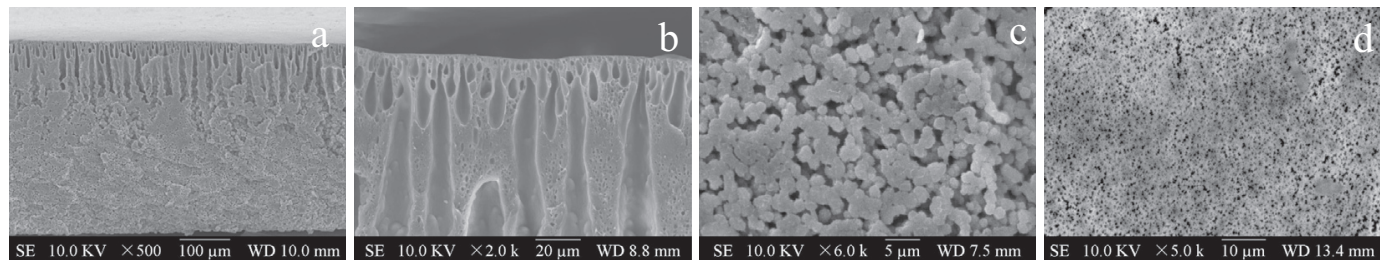

25 wt. $\%$

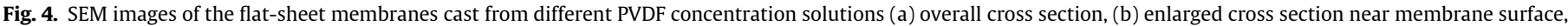
(c) sponge-like layer and (d) membrane surface.

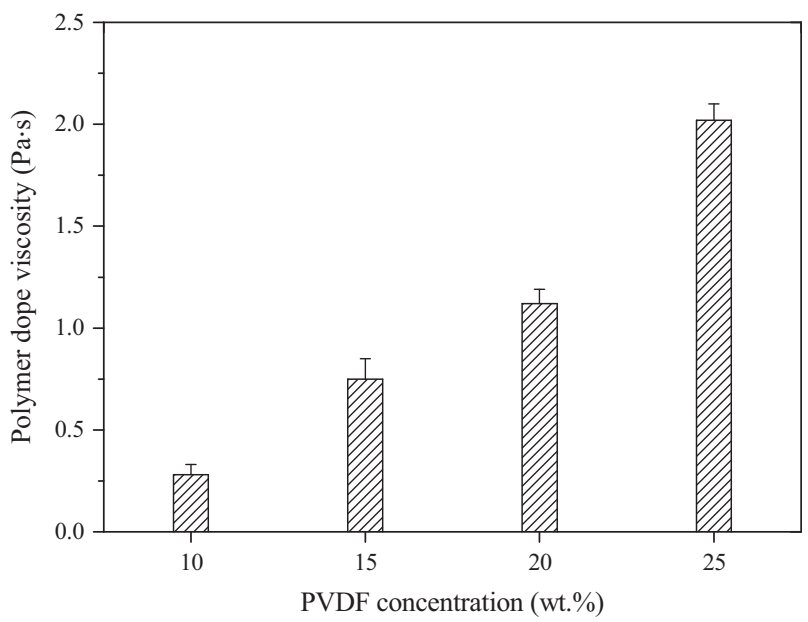

Fig. 5. Effect of PVDF concentration on the polymer dope viscosity (temperature $=50^{\circ} \mathrm{C}$, rotation speed $=500 \mathrm{rpm}$ ).

Table 2

Properties of flat-sheet membranes with different PVDF concentration.

\begin{tabular}{llllll}
\hline $\begin{array}{l}\text { PVDF } \\
(\text { wt.\% })\end{array}$ & $\begin{array}{l}\text { Porosity } \\
(\%)\end{array}$ & $\begin{array}{l}\text { Thickness } \\
(\mu \mathrm{m})\end{array}$ & $\begin{array}{l}\text { Contact } \\
\text { angle }\left(^{\circ}\right)\end{array}$ & $\begin{array}{l}\text { Mean pore size } \\
\left(\times 10^{-2} \mu \mathrm{m}\right)\end{array}$ & $\begin{array}{l}\text { Flux } \\
(\mathrm{kg} / \\
\left.\mathrm{m}^{2} \mathrm{~h}\right)\end{array}$ \\
\hline 10 & $52.72 \pm 0.8$ & $110.8 \pm 3.6$ & $65.2 \pm 1.7$ & 8.37 & 2.53 \\
15 & $46.90 \pm 1.6$ & $115.7 \pm 2.3$ & $71.3 \pm 1.9$ & 6.18 & 2.10 \\
20 & $41.50 \pm 2.3$ & $138.1 \pm 2.1$ & $76.1 \pm 1.5$ & 4.75 & 1.85 \\
25 & $38.64 \pm 2.2$ & $146.5 \pm 1.4$ & $87.7 \pm 0.3$ & 4.10 & 1.35 \\
\hline
\end{tabular}

tip and the membrane surfaces were imaged in a scan size of $2.0 \mu \mathrm{m} \times 2.0 \mu \mathrm{m}$, the surface roughness was obtained by tapping mode.

\subsection{Porosity, pore size and pore size distribution}

The porosity of the membrane was defined as the volume of the pores divided by the total volume of the membrane. The flat-sheet membrane porosity $\varepsilon$ was determined by gravimetric method and calculated by the following equation [31]:

$\varepsilon=\frac{m_{1}-m_{2}}{\rho_{L} \cdot A \cdot l}$,

where $m_{1}$ and $m_{2}$ are the weight of wet membrane and dry membrane, respectively. $\rho_{L}$ is the density of wetting liquid, $A$ is the effective area of membrane sample and $l$ is the membrane thickness. The liquid used for porosity measurement named Porefil was supported by IB-FT GmbH (Germany), its surface tension and density are $16 \mathrm{dyn} / \mathrm{cm}$ and $1.87 \mathrm{~g} / \mathrm{ml}$, respectively.

The mean point size and pore size distribution of prepared membrane were measured by using a Capillary Flow Porometer (CFP) (Porolux 1000, IB-FT GmbH, Germany). The membranes were fully wetted with the Porefil, and then the measurements were carried out following the procedure described in literature [18]. The mean point size and pore size distribution were determined with the aid of the computer software coupled to CFP.

\subsection{Desalination experiment}

DCMD experiment was carried out to evaluate the membrane permeability with the apparatus shown in Fig. 1. The membrane module presented in Fig. 2 was a plate and frame consisting of two chambers, one for the feed and the other for distillate. The flat-sheet membrane with an effective area of $7.47 \times 10^{-3} \mathrm{~m}^{2}$ was tightly clamped between the two chambers. Both chambers had a thickness of $1.0 \mathrm{~mm}$ and there were 10 flow paths with the same width of $7.0 \mathrm{~mm}$ for each chamber. The hot feed, a $35 \mathrm{~g} / \mathrm{L}$ aqueous sodium chloride solution, and cold distillate flowed concurrently from the bottom to the upper part of the module with 
Table 3

Properties of PVDF flat-sheet membranes with different non-solvent additive.

\begin{tabular}{|c|c|c|c|c|c|}
\hline Additive & Porosity (\%) & Thickness $(\mu \mathrm{m})$ & Contact angle $\left({ }^{\circ}\right)$ & Mean pore size $\left(\times 10^{-2} \mu \mathrm{m}\right)$ & Flux $\left(\mathrm{kg} / \mathrm{m}^{2} \mathrm{~h}\right)$ \\
\hline Without additive & $41.50 \pm 2.3$ & $138.1 \pm 2.1$ & $76.1 \pm 1.5$ & 4.75 & 1.85 \\
\hline Acetone & $39.2 \pm 1.7$ & $121.8 \pm 1.3$ & $88.3 \pm 0.6$ & 3.87 & 1.55 \\
\hline $\mathrm{H}_{3} \mathrm{PO}_{4}$ & $54.6 \pm 0.2$ & $145.0 \pm 0.5$ & $78.5 \pm 1.1$ & 7.45 & 6.10 \\
\hline Glycerin & $56.4 \pm 0.7$ & $138.2 \pm 1.8$ & $57.6 \pm 2.3$ & 7.62 & 6.58 \\
\hline $\mathrm{LiCl}$ & $41.0 \pm 1.4$ & $132.5 \pm 0.3$ & $85.4 \pm 1.5$ & 4.90 & 3.76 \\
\hline PEG 400 & $54.9 \pm 1.2$ & $125.6 \pm 1.6$ & $79.2 \pm 2.0$ & 6.38 & 5.13 \\
\hline
\end{tabular}
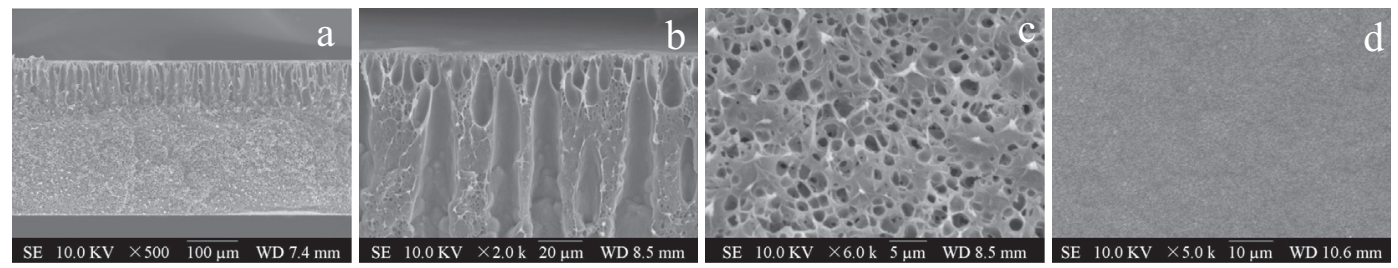

Acetone
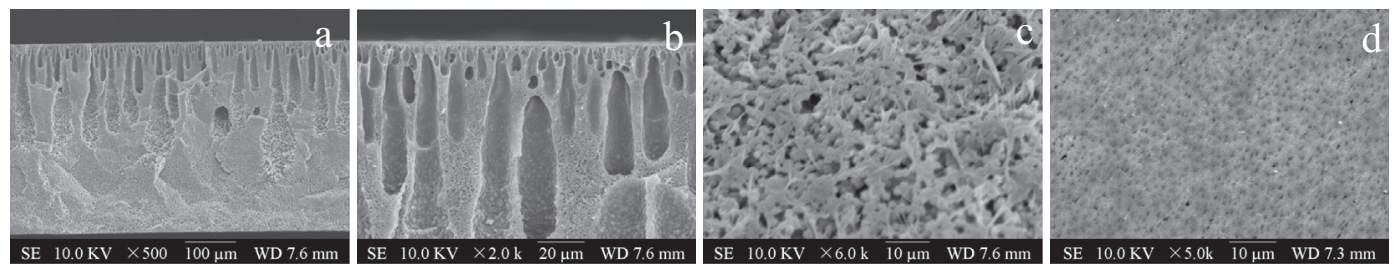

$\mathrm{H}_{3} \mathrm{PO}_{4}$
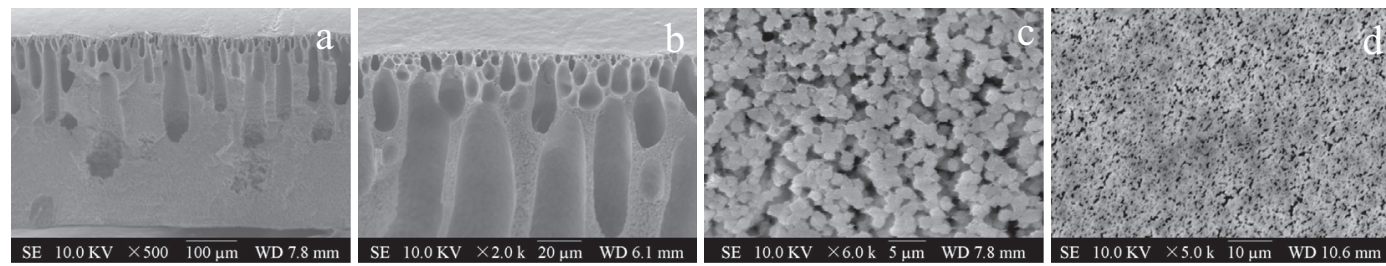

Glycerine
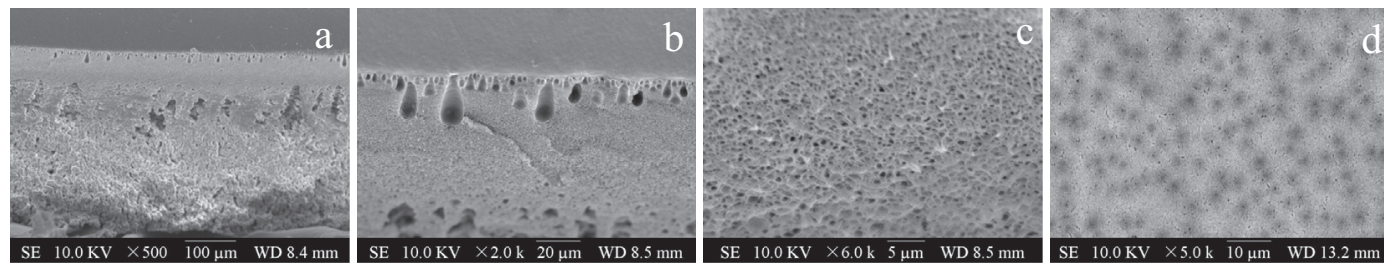

$\mathrm{LiCl}$
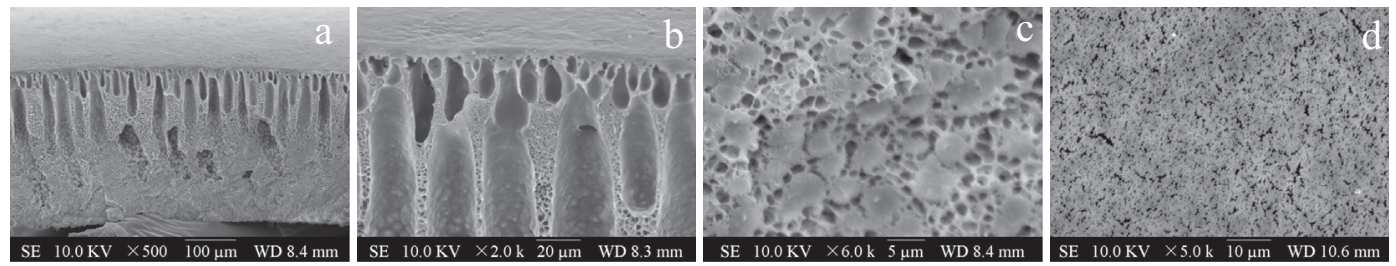

PEG 400

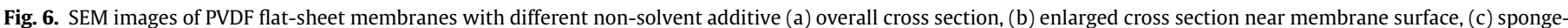
like layer and (d) membrane surface.

the help of two magnetic pumps (MP-215R, Shanghai Seisun Bumps, China). The initial volume of the feed and the distillate were $2.0 \mathrm{~L}$ and $0.25 \mathrm{~L}$, respectively. The circulation feed rate and permeate rate were adjusted by two rotameters (LZS-15, Yuyao Yinhuan Flowmeter, China) and kept constant at $70 \mathrm{~L} / \mathrm{h}$ (about $0.28 \mathrm{~m} / \mathrm{s}$ ). The fluids temperature were controlled by water baths and monitored at the inlet and outlet of the module using four Pt-100 thermoresistances connected to a digital meter (Digit RTD, model XMT-808, Yuyao Changjiang Temperature Meter Instruments, China), the inlet temperature of the hot feed and the cold distillate were kept at constant $50.0^{\circ} \mathrm{C}$ and $20.0^{\circ} \mathrm{C}$, respectively. The concentration of $\mathrm{NaCl}$ in the distillate was investigated 

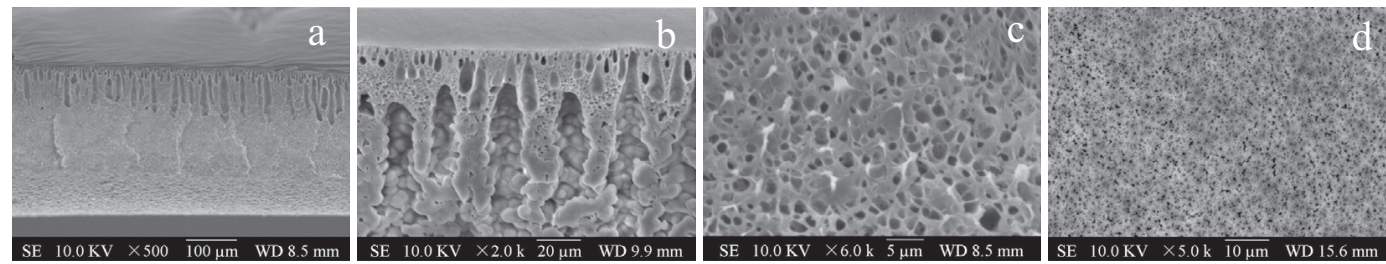

5 wt. $\%$ Acetone +1 wt. $\% \mathrm{H}_{3} \mathrm{PO}_{4}$
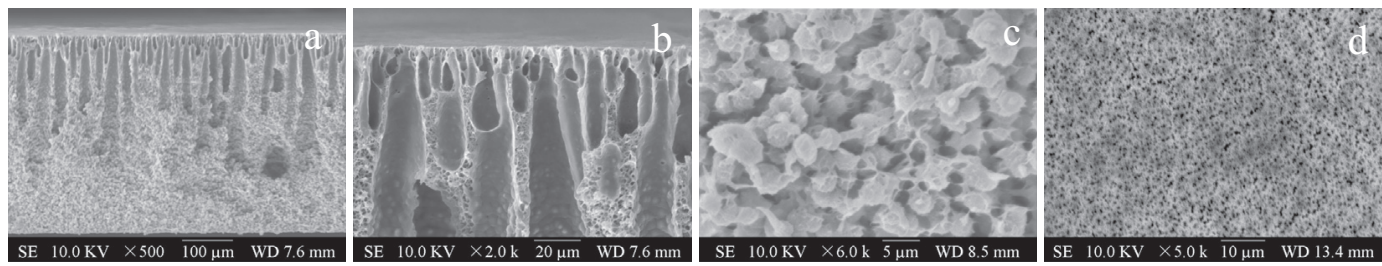

5 wt. $\%$ Acetone +3 wt. $\% \mathrm{H}_{3} \mathrm{PO}_{4}$
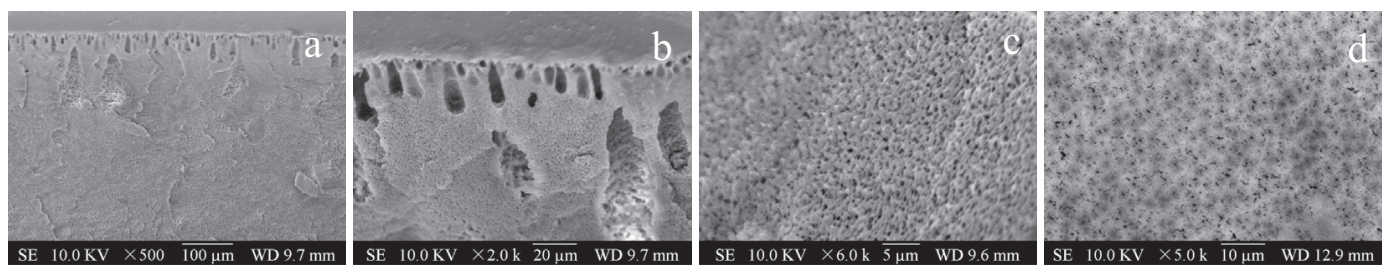

5 wt. $\%$ Acetone +5 wt. $\% \mathrm{H}_{3} \mathrm{PO}_{4}$

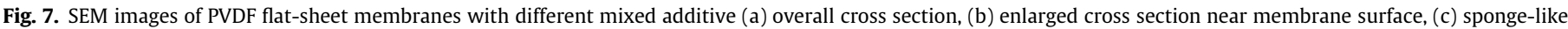
layer and (d) membrane surface.

Table 4

Properties of PVDF flat-sheet membranes with different mixed additive.

\begin{tabular}{llllll}
\hline $\begin{array}{l}\text { Additive content } \\
\left(\text { acetone }+\mathrm{H}_{3} \mathrm{PO}_{4}\right)\end{array}$ & $\begin{array}{l}\text { Porosity } \\
(\%)\end{array}$ & $\begin{array}{l}\text { Thickness } \\
(\mu \mathrm{m})\end{array}$ & $\begin{array}{l}\text { Contact } \\
\text { angle }\left(^{\circ}\right)\end{array}$ & $\begin{array}{l}\text { Mean pore size Flux } \\
\left(\times 10^{-2} \mu \mathrm{m}\right)\end{array}$ & $\begin{array}{l}(\mathrm{kg} / \\
\left.\mathrm{m}^{2} \mathrm{~h}\right)\end{array}$ \\
\hline $5 \mathrm{wt} . \%+1 \mathrm{wt} . \%$ & $53.6 \pm 0.8$ & $130.0 \pm 1.5$ & $86.5 \pm 1.7$ & 10.37 & 7.66 \\
$5 \mathrm{wt} . \%+3 \mathrm{wt} \%$ & $60.3 \pm 1.5$ & $140.7 \pm 1.8$ & $83.8 \pm 1.3$ & 12.69 & 8.97 \\
$5 \mathrm{wt} . \%+5 \mathrm{wt} . \%$ & $62.5 \pm 1.3$ & $146.3 \pm 0.6$ & $80.9 \pm 0.8$ & 10.86 & 8.03 \\
\hline
\end{tabular}

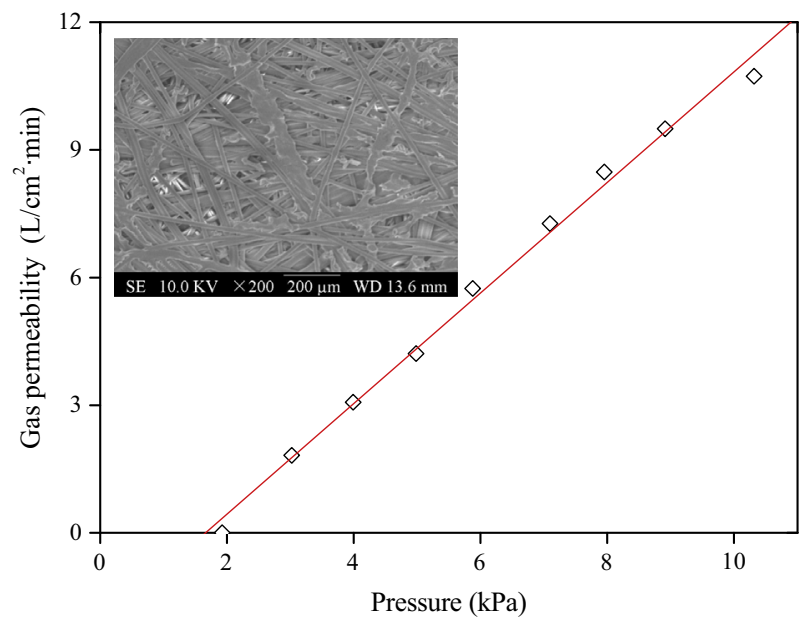

Fig. 8. SEM image and gas permeability of the polyester nonwoven fabric.

with an electric conductivity monitor (CM-230A, Shijiazhuang Create Instrumentation Technologies, China). The permeate flux of prepared membrane $J$ was calculated by the following equation:

$J=\frac{\Delta W}{A \Delta t}$ where $J$ is the permeate flux $\left(\mathrm{kg} / \mathrm{m}^{2} \mathrm{~h}\right), \Delta W$ is the quantity of distillate $(\mathrm{kg}), A$ is the effective membrane area $\left(\mathrm{m}^{2}\right)$ and $\Delta t$ is the sampling time (h). The rejection coefficient $R$ was calculated according to the following equation:

$R=\frac{C_{f}-C_{p}}{C_{f}}$,

where $C_{f}$ and $C_{p}$ are the concentration of the feed and permeate, respectively.

\section{Result and discussion}

\subsection{Effect of solvent}

The proper solvent selection is essential in design and engineering of a membrane suitable for membrane process. DMF, DMAc, DMSo, and NMP were selected as the polymer PVDF solvent in present research. The SEM micrographs of the prepared membranes cast from 20 wt.\% PVDF solutions are shown in Fig. 3.

It can be found all the membranes exhibited inhomogeneous structures due to the presence of large voids and cavities with different size and shape beneath the skin. For the membranes cast form different solvent, the thickness of skin layer was in the range of 20-50 nm. The DMF cast membrane presented a small quantity of short finger-like cavities beneath the skin. The structure of the porous sublayer was globular and the polymer globules looked fairly uniform over the entire cross-section part. For the membrane cast from DMAc, the cavities extended through more than half of the membrane thickness, the cross-section was spongy and integrated with different size globules, it was apparent that the globules in the end of finger-like cavities were compacted and larger than those in the cross-section. By using NMP or DMSo as solvent, cavities grew in breadth and length towards the bottom of the membrane without a well defined shape. The cross-section of the membrane cast from DMSo was full of globules with regular shape 
and size, the NMP cast membrane showed a spongy and porous cross-section.

The properties of the membranes cast from different solvent are listed in Table 1. The membrane used DMF as solvent obtained the maximum contact angle, indicating that its hydrophobicity was the best in the four membranes. Although the permeate flux of the membrane cast from NMP was the highest, the salt rejection was below 95\% and far lower than that of other three membranes, which can be attributed to partial wetting phenomenon because of a small amount large-size pores existed on the membrane surface. The permeate flux and porosity of the DMSo cast membrane were higher than those of the membrane from DMAc, but DMAc solvent had a good solubility to PVDF polymer as well as for phase dispersion compared with DMSo.

\subsection{Effect of PVDF concentration}

Polymer concentration in dope solution plays an important part in determining membrane properties. The flat-sheet membranes were prepared by using DMAc as solvent and PVDF concentration in different dope solution was in the range of $10-25 \mathrm{wt} . \%$, the membrane SEM images are presented in Fig. 4.

It can be obviously seen that the increase of polymer concentration in dope solution led to a reduction of both the number and the size of cavities. The structure of the porous sublayer was spongy and very loose for the membrane from $10 \mathrm{wt} . \%$ to $15 \mathrm{wt} . \%$ PVDF dope. For the membrane cast by $20 \mathrm{wt}$.\% PVDF dope as shown in Fig. 3, the globules began to appear in the end of finger-like cavities and they were also disconnectedly distributed throughout the cross-section. When the PVDF content increased to $25 \%$ in the solution, the finger-like cavities became shorter and narrower and the cross-section consisted of a large number of globules with uniform size. As presented in Fig. 5, the solution viscosity increased with polymer concentration increasing, which would hinder the penetration of the non-solvent during the immersion step. As a result, the cavities formed in membrane cross-section became shorter and narrower, and the membrane thickness increased for delayed phase separation. The lower is the dope solution viscosity, the higher is the occurrence of cavities in the membrane.

Table 2 lists the fabricated flat-sheet membrane properties. The porosity, mean pore size and permeate flux reduced with the polymer concentration increase and this trend corresponded with the membrane morphology. It can also be found that the membrane prepared from higher polymer concentration exhibited higher contact angle. According to the Laplace-Young equation [32], the membrane with larger-size pores meant lower resistance for water entering. As a result, the salt solution can gradually penetrate into the porous surface, which will cause membrane wetting and salt rejection decline. Due to the existence of pores with diameter larger than $1.0 \mu \mathrm{m}$ in partial area of the prepared membrane,
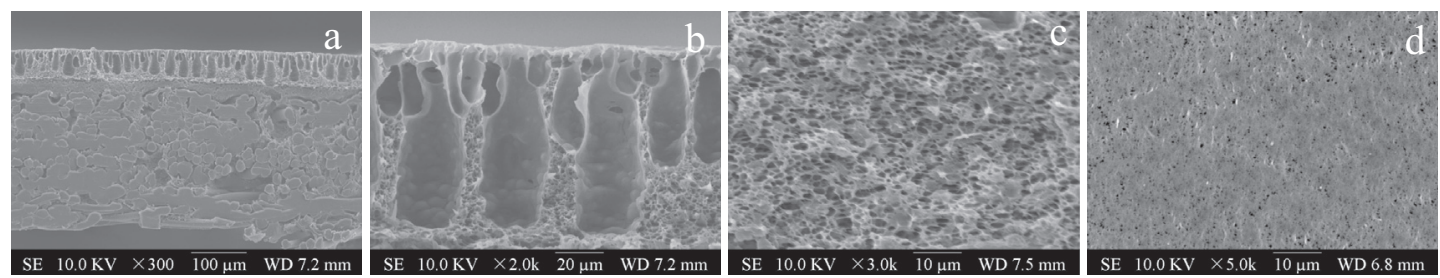

Without additive
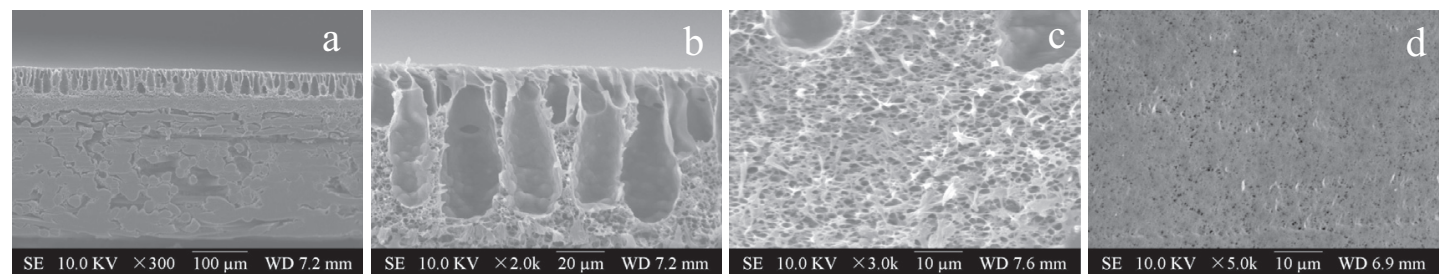

5 wt. $\%$ Acetone
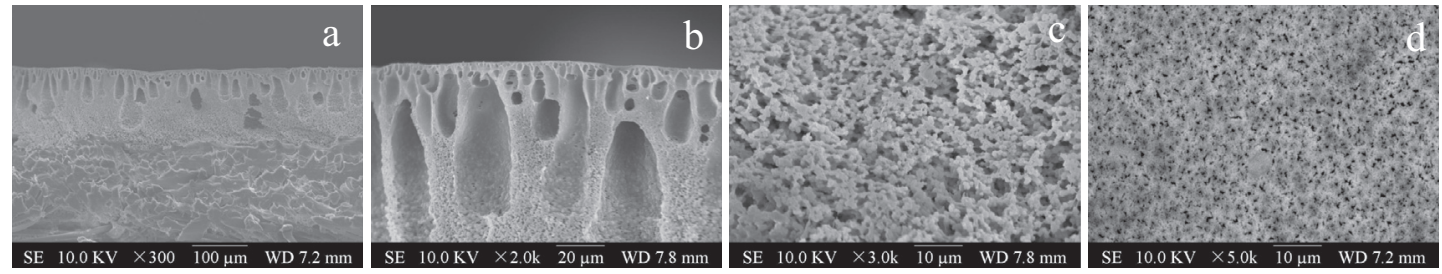

5 wt. $\% \mathrm{H}_{3} \mathrm{PO}_{4}$
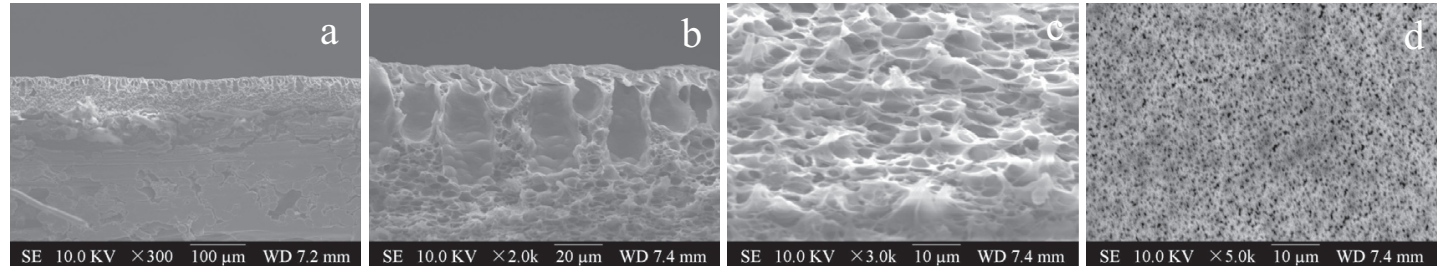

5 wt. $\%$ Acetone +3 wt. $\% \mathrm{H}_{3} \mathrm{PO}_{4}$

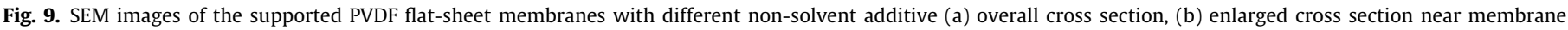
surface, (c) sponge-like layer and (d) membrane surface. 
although the membrane cast from 10 wt.\% to 15 wt.\% PVDF dope obtained higher permeate flux, the salt rejection was lower than $90 \%$, which meant that these two membranes were not suitable for DCMD process.

\subsection{Effect of non-solvent additive}

The influence of acetone, phosphoric acid, glycerine, $\mathrm{LiCl}$ and PEG 400 as the non-solvent additive was investigated. Five dope solutions containing $20 \mathrm{wt} . \%$ PVDF polymer were prepared by using DMAc as solvent and the concentration of non-solvent additives in each dope was $5 \mathrm{wt} . \%$.

Although the membrane using glycerin as additive obtained the highest permeate flux compared to other four membranes, the retention to salt for this membrane was too poor and the membrane contact angle was about $57.6^{\circ}$, which indicated that the membrane was hydrophilic and the glycerine was not a suitable non-solvent additive for hydrophobic membrane preparation. The contact angles of other four membranes were much higher than that of the membrane prepared using glycerin as additive and the salt rejection exceeded $99 \%$ for the membranes using acetone, phosphoric acid, $\mathrm{LiCl}$ and PEG 400 as additive. The fabricated membrane properties are listed in Table 3, it can be seen that the mean pore diameter and permeate flux of the membrane using $\mathrm{H}_{3} \mathrm{PO}_{4}$ as non-solvent additive were higher than those of the membranes using acetone, $\mathrm{LiCl}$ and PEG 400 as additive. The addition of acetone made the prepared membrane obtain the smallest pore size and porosity, and the permeate flux was only $1.55 \mathrm{~kg} / \mathrm{m}^{2} \mathrm{~h}$, even less than that of the membrane without non-additive addition.

The change of membrane properties can be associated with the difference of the thermodynamic and kinetic properties of the dope solution with different non-solvent additive. The acetone was volatile and it made the polymer concentration increase in the gasdope contact interface, so a dense top skin layer was formed and the mean pore size became small. Because of the good compatibility with the solvent DMAc and the coagulant water for glycerin, the double diffusion rate between solvent and non-solvent was accelerated, which increased the phase demixing rate and made the finger-like cavities become longer and wider and the membrane pore diameter also get larger as shown in Fig. 6. As a water-soluble polymer, the non-solvent additive PEG increased the thermodynamic instability of the dope solution in reaction with water, which facilitated a rapid phase demixing and resulted in macrovoids and higher porosity. In Fig. 6, it can also be seen that the cross-section of the membrane with PEG as additive was spongy and integrated with some globules and the membrane skin looked more porous, although the pore size was inhomogeneous. The addition of $\mathrm{H}_{3} \mathrm{PO}_{4}$ or $\mathrm{LiCl}$ increased the viscosity of the polymer dope. As for the non-solvent additive $\mathrm{H}_{3} \mathrm{PO}_{4}$ addition, the appropriate increase of dope viscosity can not only help in the formation of a casting membrane but also help in improve the membrane porosity and pore size. $\mathrm{LiCl}$ possessed strong interactions with the polymer and solvent, the addition of it can enhance the viscosity of the dope solution significantly. The strong interactions among the components of the dope tended to delay the dope precipitation, so the macrovoids became smaller, the membrane skin got thick, both the number and the size of the pore distributed on membrane surface reduced.

\subsection{Effect of mixed additive}

Although the addition of acetone resulted in the formation of a membrane with a dense top skin layer and small pore size, the thermodynamic homogeneity and stability of the dope got enhanced by swelling action of the acetone and this can make the prepared membrane exhibit good uniformity either on
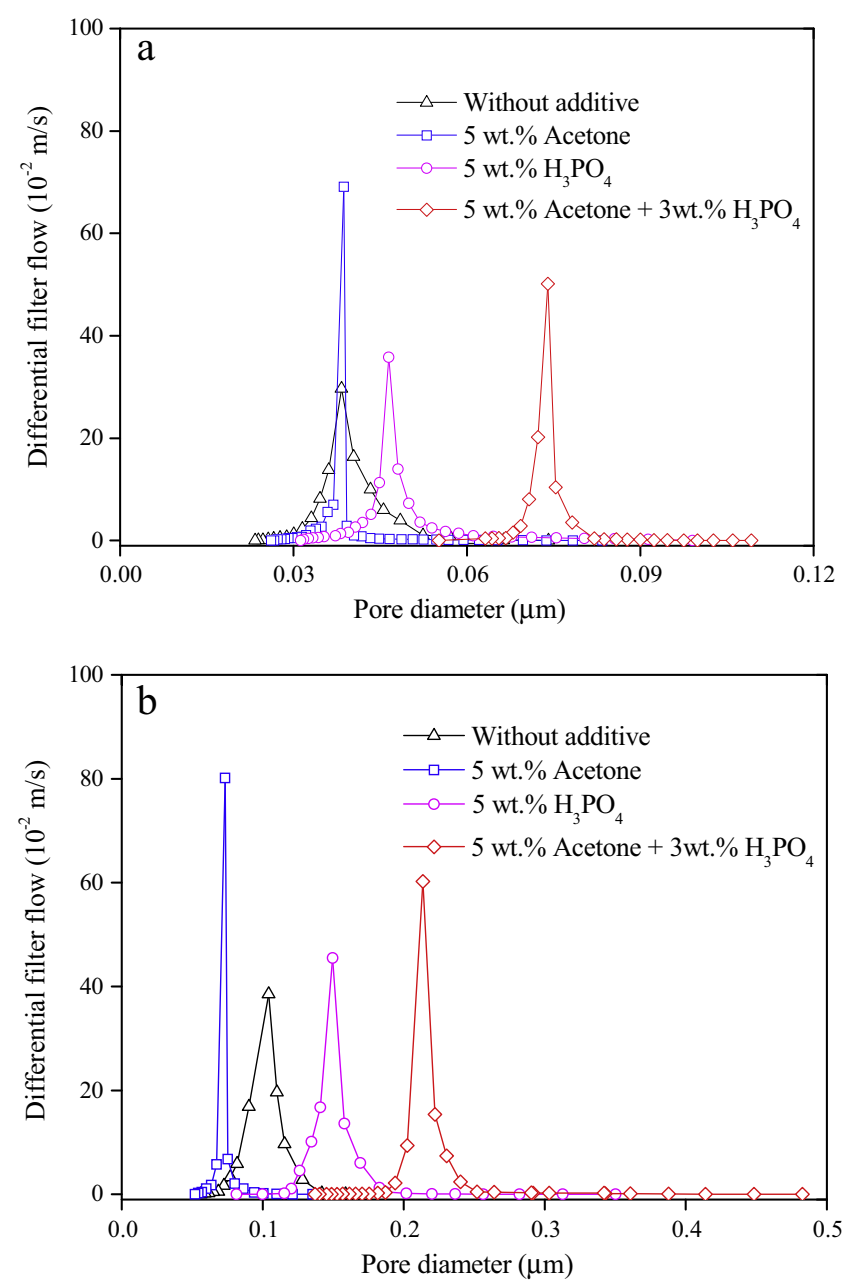

Fig. 10. Pore size distribution of PVDF flat-sheet membranes with different additive (a) the unsupported membranes and (b) the supported membranes.

sponge-like layer or on membrane surface. It has been reported that the acetone as the second non-solvent additive added into the dope was beneficial to readjust membrane structure and obtain a higher permeate flux due to the synergistic effect of the mixed additive [33]. According to the research results of different nonsolvent additive, the $\mathrm{H}_{3} \mathrm{PO}_{4}$ was selected to mix with the acetone and the effect of the mixture as non-solvent additive was investigated. The dope solutions containing $20 \mathrm{wt}$.\% PVDF polymer were prepared by using DMAc as solvent, the mixed additive contained 5 wt.\% acetone and the $\mathrm{H}_{3} \mathrm{PO}_{4}$ content in the dope was in the range of $1-5$ wt.\%.

The SEM images of the prepared membranes are shown in Fig. 7. It can be found that the variation of $\mathrm{H}_{3} \mathrm{PO}_{4}$ content in the

Table 5

Properties of the supported PVDF flat-sheet membranes with different non-solvent additive.

\begin{tabular}{lllllr}
\hline Additive & $\begin{array}{l}\text { Porosity } \\
(\%)\end{array}$ & $\begin{array}{l}\text { Thickness } \\
(\mu \mathrm{m})\end{array}$ & $\begin{array}{l}\text { Mean pore } \\
\text { size } \\
\left(\times 10^{-2} \mu \mathrm{m}\right)\end{array}$ & $\begin{array}{l}\text { Maximum } \\
\text { pore size } \\
\left(\times 10^{-2} \mu \mathrm{m}\right)\end{array}$ & \begin{tabular}{l}
$\begin{array}{l}\text { Flux } \\
(\mathrm{kg} / \\
\left.\mathrm{m}^{2} \mathrm{~h}\right)\end{array}$ \\
\hline $\begin{array}{l}\text { Without } \\
\text { additive }\end{array}$
\end{tabular} \\
$\begin{array}{l}\text { Acetone } \\
\mathrm{H}_{3} \mathrm{PO}_{4}\end{array}$ & $49.16 \pm 1.9$ & $207.3 \pm 2.7$ & 10.46 & 15.87 & 5.34 \\
Acetone $+\mathrm{H}_{3} \mathrm{PO}_{4}$ & $54.93 \pm 0.9$ & & & \\
\end{tabular}


dope solutions had a strong influence on membrane morphology. The membrane with $5 \mathrm{wt} . \%$ acetone and $3 \mathrm{wt} . \% \mathrm{H}_{3} \mathrm{PO}_{4}$ as mixed additive exhibited the thinnest top skin, the longest and broadest finger-like cavities, the pore size of membrane surface was also the largest among these three membranes. The properties of prepared membranes are listed in Table 4. For all the three membranes, the permeate flux was higher than that of the membrane using alone acetone or $\mathrm{H}_{3} \mathrm{PO}_{4}$ as non-solvent additive, which demonstrated that the synergistic effect of the mixed additive was helpful to optimize the membrane permeability. The mean pore diameter and permeate flux of the membrane using $5 \mathrm{wt} . \%$ acetone and $3 \mathrm{wt} . \% \mathrm{H}_{3} \mathrm{PO}_{4}$ as mixed additive were higher than those of another two membranes, which can be attributed to the process of membrane formation. Due to the addition of $\mathrm{H}_{3} \mathrm{PO}_{4}$ into polymer

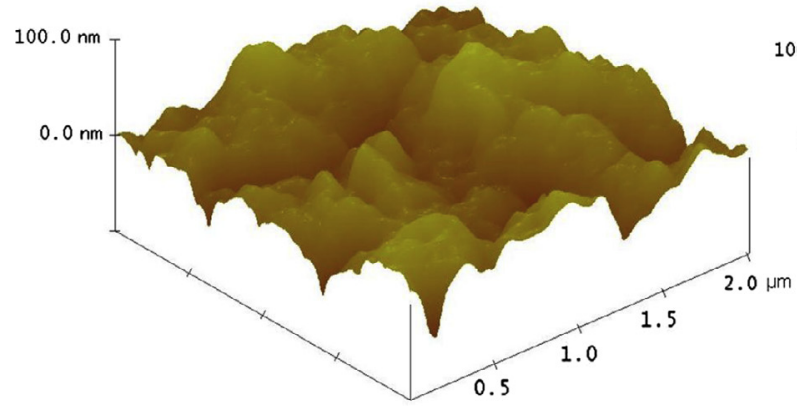

Without additive

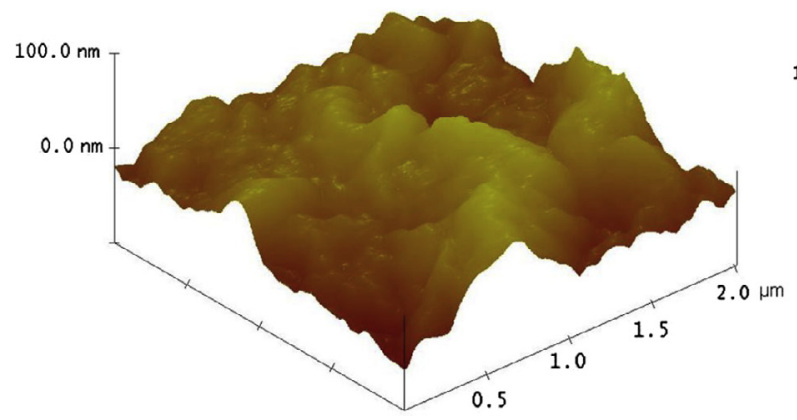

$\mathrm{H}_{3} \mathrm{PO}_{4}$

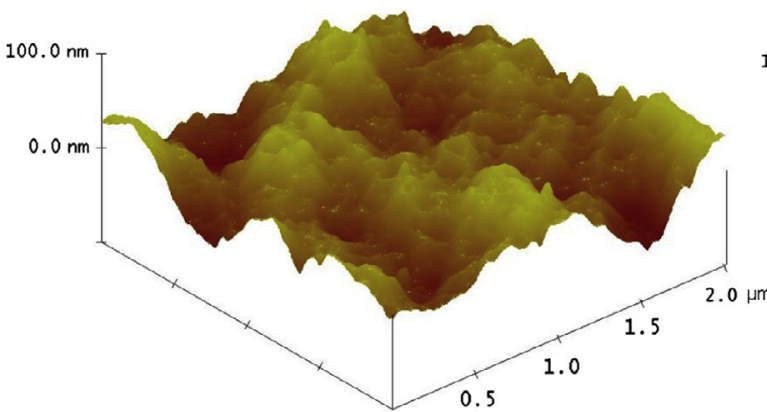

Without additive

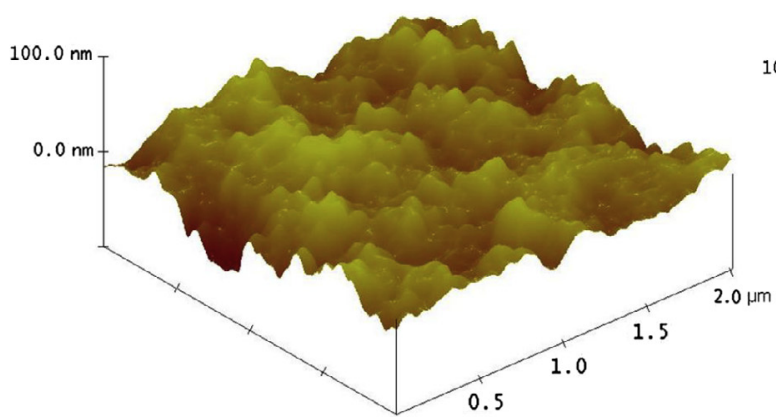

$\mathrm{H}_{3} \mathrm{PO}_{4}$

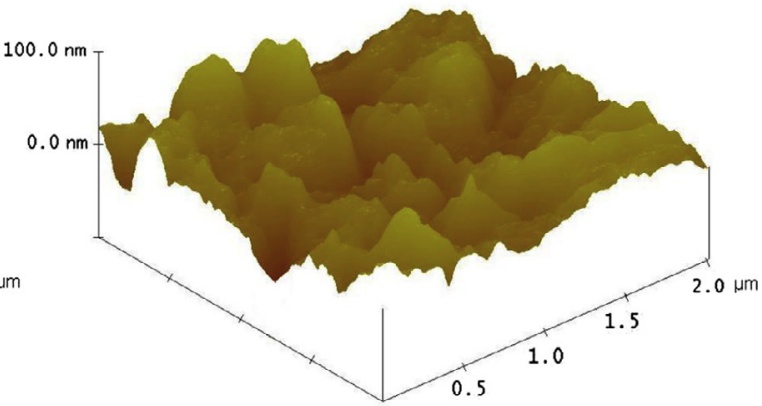

Acetone

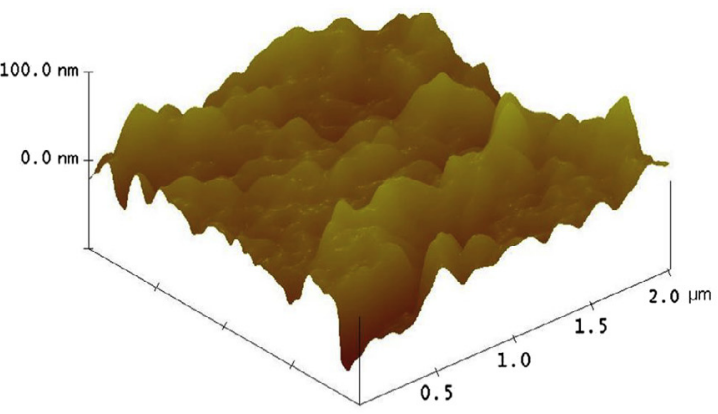

Acetone $+\mathrm{H}_{3} \mathrm{PO}_{4}$

(a)

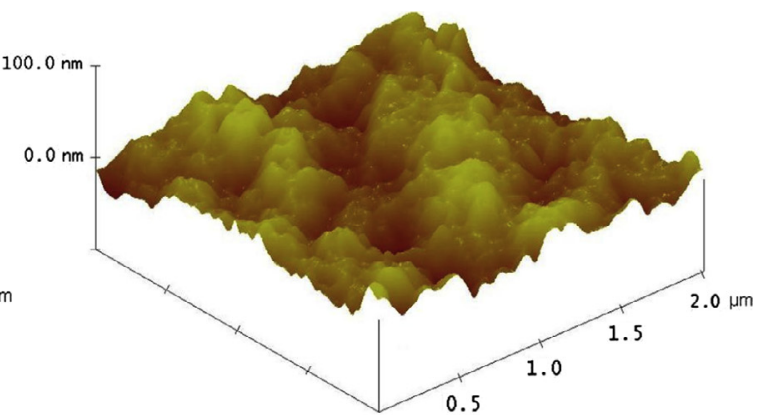

Acetone

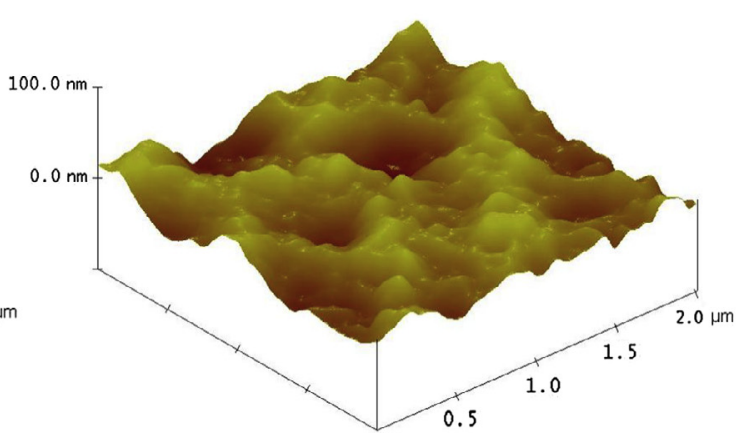

(b)

Fig. 11. AFM images of the surfaces of PVDF flat-sheet membranes with different additive (a) the unsupported membranes and (b) the supported membranes. 
Table 6

Roughness parameters and contact angle values of the prepared membranes.

\begin{tabular}{|c|c|c|c|c|c|c|c|}
\hline Flat-sheet membrane & Additive & $R_{a}(\mathrm{~nm})$ & $R_{q}(\mathrm{~nm})$ & $R_{\max }(\mathrm{nm})$ & $\mu_{n}(\mathrm{~nm})$ & $R_{a} / \mu_{n}$ & Contact angle $\left({ }^{\circ}\right)$ \\
\hline \multirow{4}{*}{ Unsupported membrane } & Without additive & 23.08 & 29.00 & 198.54 & 109.38 & 0.21 & $76.1 \pm 1.5$ \\
\hline & Acetone & 20.68 & 25.44 & 180.37 & 82.72 & 0.25 & $88.3 \pm 0.6$ \\
\hline & $\mathrm{H}_{3} \mathrm{PO}_{4}$ & 27.89 & 33.35 & 253.69 & 132.81 & 0.21 & $78.5 \pm 1.1$ \\
\hline & Acetone $+\mathrm{H}_{3} \mathrm{PO}_{4}$ & 21.85 & 28.53 & 214.97 & 91.43 & 0.24 & $83.8 \pm 1.3$ \\
\hline \multirow[t]{4}{*}{ Supported membrane } & Without additive & 14.35 & 18.05 & 138.75 & 76.64 & 0.19 & $71.9 \pm 1.1$ \\
\hline & Acetone & 12.49 & 14.98 & 102.76 & 51.97 & 0.24 & $86.1 \pm 0.5$ \\
\hline & $\mathrm{H}_{3} \mathrm{PO}_{4}$ & 15.26 & 19.43 & 115.38 & 71.45 & 0.21 & $76.5 \pm 1.2$ \\
\hline & Acetone $+\mathrm{H}_{3} \mathrm{PO}_{4}$ & 13.37 & 15.79 & 105.86 & 60.51 & 0.22 & $82.6 \pm 0.7$ \\
\hline
\end{tabular}

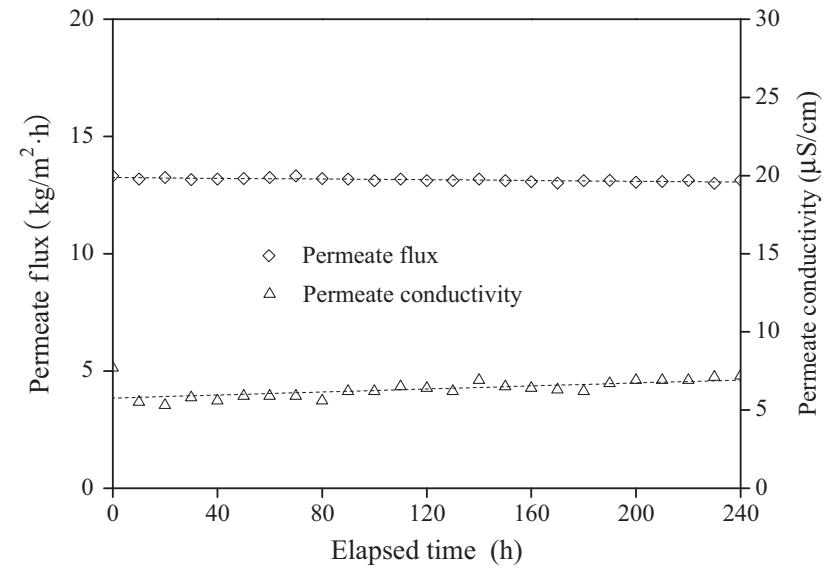

Fig. 12. Variation of the membrane permeability along with operating time.

dope, the dope viscosity increased. Although the appropriate increase of dope viscosity can not only help in the formation of a casting membrane but also enhance the membrane porosity and mean pore size, the excess addition of $\mathrm{H}_{3} \mathrm{PO}_{4}$ cause the dope become too sticky. The high dope viscosity was harmful for the double diffusion rate between solvent and non-solvent, so the phase separation rate declined and the mean pore diameter of the prepared membranes became smaller, and the dense membrane structure formed at last. In this case, the excessive addition of $\mathrm{H}_{3} \mathrm{PO}_{4}$ would lead the membrane permeability to deteriorate.

\subsection{Effect of nonwoven fabric}

Because of the significant shrinkage of the prepared pure PVDF flat-sheet membranes during drying process, the mean pore size and membrane porosity would decline, which induced the decrease of membrane permeate flux. The maximum shrinkage can reach as high as $46 \%$ for the pure PVDF flat-sheet membrane. To prevent the membrane shrinkage, the PVDF/nonwoven fabric flat-sheet composite membranes were prepared by introducing polyester nonwoven fabric as the support layer. In addition, the polyester nonwoven fabric owns stronger mechanical strength and the flat-sheet composite membranes can withstand the intense hydraulic impact and flow disturbance, which are very important from an industrial application standpoint.

The flat-sheet composite membrane used a polyester nonwoven fabric (100.6 $\pm 0.3 \mathrm{~g} / \mathrm{m}^{2}$, Teijin Ltd., Japan) as the support layer. The SEM image and gas permeability of the nonwoven fabric are presented in Fig. 8. To compared with the prepared pure PVDF membranes, four dope solutions containing 20 wt.\% PVDF polymer were prepared by using DMAc as solvent. In these four dope solutions, one was without additive addition, the other three contained 5 wt.\% acetone, 5 wt.\% phosphoric acid, 5 wt.\% acetone and 3 wt.\% phosphoric acid mixture as additive, respectively.
The membrane SEM images are presented in Fig. 9. It can be found that all the membranes with polyester nonwoven fabric as support obtained broader and shorter finger-like cavities compared with the corresponding membranes without nonwoven fabric support and the cross-section of the composite membranes became looser. Because the membrane shrinkage was prevented effectively, the membrane pore size was enhanced and the pore size distribution got wider as showed in Fig. 10. Although the maximum pore size of the composite membranes increased obviously compared with that of the pure PVDF membranes, the maximum pore size of the composite membranes was less than $0.5 \mu \mathrm{m}$ as listed in Table 5 and the composite membranes still exhibited good salt rejection.

The three-dimensional surface images of the flat-sheet membranes can be observed in Fig. 11. The nonwoven fabric support caused the roughness of the composite membranes surface decline. Table 6 lists the measured values of membrane surfaced roughness by AFM, $R_{a}, R_{q}$ and $R_{\max }$ are the average roughness, the root mean square roughness and the maximum roughness, respectively. The membrane hydrophilic/hydrophobic property was related to membrane surface nodule size and roughness. The membrane surface nodule size distribution can be obtained with the aid of the computer software coupled to AFM and the calculated mean nodule size $\left(\mu_{n}\right)$ is listed in Table 6. It can be found that the nodule size of the composite membrane was smaller than that of the pure PVDF membrane. According to the modified Young's equation proposed by Rafat et al. [34], the membrane surface contact angle was determined by the ratio of the mean surface roughness to the mean surface nodule size $\left(R_{a} / \mu_{n}\right)$, the contact angle would become higher with an increase in $R_{a} / \mu_{n}$ for PVDF membrane. Although both the membrane surface nodule size and roughness were smaller than those of the pure PVDF membranes, the contact angles declined slightly for the composite membranes.

\subsection{Performance stability}

It is important to maintain the permeability and solute rejection during the practical application for the prepared membrane. The PVDF/nonwoven fabric composite membrane using 5 wt.\% acetone and $3 \mathrm{wt} . \% \mathrm{H}_{3} \mathrm{PO}_{4}$ as mixed additive was selected to be applied in $240 \mathrm{~h}$ continuous desalination process of sodium chloride solution to investigate its retaining performance stability. The feed $\mathrm{NaCl}$ concentration was kept at $35 \mathrm{~g} / \mathrm{L}$ and other operating parameters of the DCMD process were in accordance with the permeability tests. The result of desalination performance is shown in Fig. 12. It can be seen that the permeate flux maintains about $12.50 \mathrm{~kg} /$ $\mathrm{m}^{2} \mathrm{~h}$ during experiment and there are no obvious changes of permeate flux. The permeate conductivity stabilized at about 5.3$7.5 \mu \mathrm{S} / \mathrm{cm}$. All of these demonstrated that this composite membrane had a stable permeability and solute rejection and it may be of great potential to be utilized in the DCMD process. 
Table 7

Comparison of the permeate flux obtained in this study with the literature for DCMD process.

\begin{tabular}{|c|c|c|c|c|c|c|c|c|}
\hline \multirow[t]{2}{*}{ Membrane } & \multirow[t]{2}{*}{ Reference } & \multirow{2}{*}{$\begin{array}{l}\text { Permeate flux } \\
\left(\mathrm{kg} / \mathrm{m}^{2} \mathrm{~h}\right)\end{array}$} & \multicolumn{3}{|l|}{ Feed solution } & \multicolumn{2}{|c|}{ Permeate solution } & \multirow[t]{2}{*}{ Configuration } \\
\hline & & & $\begin{array}{l}\mathrm{NaCl} \\
\text { concentration } \\
(\mathrm{g} / \mathrm{L})\end{array}$ & $\begin{array}{l}\text { Inlet } \\
\text { temperature } \\
\left({ }^{\circ} \mathrm{C}\right)\end{array}$ & $\begin{array}{l}\text { Flow rate } \\
(\mathrm{m} / \mathrm{s})\end{array}$ & $\begin{array}{l}\text { Inlet } \\
\text { temperature } \\
\left({ }^{\circ} \mathrm{C}\right)\end{array}$ & $\begin{array}{l}\text { Flow rate } \\
(\mathrm{m} / \mathrm{s})\end{array}$ & \\
\hline PTFE (Membrane Solutions) & [35] & 12.10 & 10 & 50 & 0.36 & 20 & 0.36 & $\begin{array}{l}\text { Counter- } \\
\text { current }\end{array}$ \\
\hline PTFE (Changqi) & [36] & 11.88 & 10 & 50 & 0.095 & 20 & 0.114 & $\begin{array}{l}\text { Counter- } \\
\text { current }\end{array}$ \\
\hline PTFE (FGLP1425, Millipore) & {$[25]^{\mathrm{a}}$} & 12.25 & Distillate water & 50 & $60 \mathrm{~L} / \mathrm{h}$ & 15 & $60 \mathrm{~L} / \mathrm{h}$ & $\begin{array}{l}\text { Counter- } \\
\text { current }\end{array}$ \\
\hline PVDF (GVHP, Millipore) & {$[6]$} & 10.37 & Pure water & 50 & 2.59 & 20 & 4.67 & $\begin{array}{l}\text { Counter- } \\
\text { current }\end{array}$ \\
\hline PVDF (HVHP, Millipore) & [6] & 11.67 & Pure water & 50 & 2.59 & 20 & 4.67 & $\begin{array}{l}\text { Counter- } \\
\text { current }\end{array}$ \\
\hline $\begin{array}{l}\text { PVDF electrospun nanofibrous } \\
\text { membrane (Laboratory scale) }\end{array}$ & {$[37]^{\mathrm{a}}$} & 18.00 & 30 & 50 & $500 \mathrm{rpm}$ & 20 & $500 \mathrm{rpm}$ & $\begin{array}{l}\text { Counter- } \\
\text { current }\end{array}$ \\
\hline F2.4 (Laboratory scale) & {$[38]^{\mathrm{a}}$} & 7.20 & 17.6 & 55 & $22 \mathrm{~L} / \mathrm{h}$ & 20 & $12 \mathrm{~L} / \mathrm{h}$ & Concurrent \\
\hline $\begin{array}{l}\text { PVDF/nonwoven fabric composite } \\
\text { membrane (Laboratory scale) }\end{array}$ & $\begin{array}{l}\text { This } \\
\text { study }\end{array}$ & 12.45 & 35 & 50 & 0.28 & 20 & 0.28 & Concurrent \\
\hline
\end{tabular}

a The feed and permeate flow rates in $\mathrm{m} / \mathrm{s}$ were not provided in Refs. [25,37,38].

\subsection{Comparison with other flat-sheet membranes}

Table 7 lists a performance comparison between the current work and the previous investigations. It is found that the prepared flat-sheet composite membrane in this work have comparable or even better performance than commercially available flat-sheet membranes for the desalination of salt solution. The permeate flux of the PVDF nanofibrous membrane fabricated by Essalhi and Khayet [37] was higher than the flux obtained in this study. But it should be noted that the PVDF nanofibrous membrane was prepared via electrospinning, and there was no "blind pore" in the membrane and the porosity was also higher than that of the membrane prepared through coating and wet phase inversion process. However, the mechanical strength of the PVDF nanofibrous membrane was very poor compared with that of the prepared flat-sheet composite membrane. On the other hand, as far as we known, the industrial implementation of hydrophobic PVDF nanofibrous membrane fabrication is not yet feasible because of the low production of electrospinning. It is believed that if the membrane preparation optimizations which were attempted in this work are accompanied with higher feed temperature, higher flow rate, lower cold distillate temperature and more efficient module designs to improve the flow pattern and diminish the polarization effect, even higher flux is achievable in DCMD process.

\section{Conclusions}

The PVDF flat-sheet membranes for DCMD were prepared through coating and wet phase inversion process. The effects of solvent, polymer concentration, non-solvent additive and nonwoven fabric on the morphology, porosity, pore size, hydrophobicity and permeability of the resultant flat-sheet membranes were investigated. The following conclusions were obtained:

(1) The membrane using DMAc as solvent obtained good permeability, and the polymer dope containing $20 \mathrm{wt} . \%$ PVDF was the most suitable for the preparation of hydrophobic flat-sheet membrane.

(2) The PVDF flat-sheet membranes with the use of different non-solvent additives such as acetone, phosphoric acid, glycerine, $\mathrm{LiCl}$ and PEG 400 were prepared and it was found that the membrane using $5 \mathrm{wt} . \%$ acetone and $3 \mathrm{wt} . \% \mathrm{H}_{3} \mathrm{PO}_{4}$ as mixed additive had the highest permeate flux.
(3) Since the nonwoven fabric can prevent the membrane shrinkage, the pore size of the PVDF/nonwoven fabric composite membrane was enhanced. Although the nonwoven fabric caused the membrane surface roughness and nodule size decline, the contact angle only decreased slightly compared with that of the corresponding pure PVDF membrane.

(4) During the desalination process of $35 \mathrm{~g} / \mathrm{L} \mathrm{NaCl}$ solution, the highest flux of the prepared flat-sheet was obtained from the PVDF/nonwoven fabric composite membrane using $5 \mathrm{wt} . \%$ acetone and $3 \mathrm{wt} . \% \mathrm{H}_{3} \mathrm{PO}_{4}$ as mixed additive. The $240 \mathrm{~h}$ continuous experiment results demonstrated that this composite membrane had a stable permeability and solute rejection, and it may be of great potential to be utilized in DCMD process.

\section{Acknowledgments}

Financial support provided by the National Natural Science Foundation of China (Nos. 51138008, 51108445), Science and Technology Plan Project of Beijing Municipality of China (No. Z131109002813040) and the special fund from the State Key Laboratory of Environmental Aquatic Chemistry (No. 13Z04ESPCT) are gratefully acknowledged.

\section{References}

[1] M.S. El-Bourawi, Z. Ding, R. Ma, M. Khayet, A framework for better understanding membrane distillation separation process, J. Membr. Sci. 285 (2006) 4-29.

[2] A.O. Imdakm, M. Khayet, T. Matsuura, A Monte Carlo simulation model for vacuum membrane distillation process, J. Membr. Sci. 306 (2007) 341-348.

[3] A.C.M. Franken, J.A.M. Nolten, M.H.V. Mulder, D. Bargeman, C.A. Smolders, Wetting criteria for the applicability of membrane distillation, J. Membr. Sci. 33 (1987) 315-328.

[4] M. Gryta, M. Barancewicz, Influence of morphology of PVDF capillary membranes on the performance of direct contact membrane distillation, J. Membr. Sci. 358 (2010) 158-167.

[5] M. Gryta, Influence of polypropylene membrane surface porosity on the performance of membrane distillation process, J. Membr. Sci. 287 (2007) 6768.

[6] J. Phattaranawik, R. Jiraratananon, A.G. Fane, Effect of pore size distribution and air flux on mass transport in direct contact membrane distillation, J. Membr. Sci. 215 (2003) 75-85.

[7] R.T. Huo, Z.Y. Gu, K.J. Zuo, G.M. Zhao, Preparation and properties of PVDF-fabric composite membrane for membrane distillation, Desalination 249 (2009) 910913. 
[8] J.J. Kim, T.S. Jang, Y.D. Kwon, U.Y. Kim, S.S. Kim, Structural study of microporous polypropylene hollow fiber membranes made by the meltspinning and cold-stretching method, J. Membr. Sci. 93 (1994) 209-215.

[9] H.L. Zhu, H.J. Wang, F. Wang, Y.H. Guo, H.P. Zhang, J.Y. Chen, Preparation and properties of PTFE hollow fiber membranes for desalination through vacuum membrane distillation, J. Membr. Sci. 446 (2013) 145-153.

[10] D.Y. Hou, J. Wang, X.C. Sun, Z.G. Ji, Z.K. Luan, Preparation and properties of PVDF composite hollow fiber membranes for desalination through direct contact membrane distillation, J. Membr. Sci. 405-406 (2012) 185-200.

[11] M. Khayet, Membranes and theoretical modelling of membrane distillation: a review, Adv. Colloid Interface Sci. 164 (2011) 56-88.

[12] M. Tomaszewska, Preparation and properties of flat-sheet membranes from poly(vinylidene fluoride) for membrane distillation, Desalination 104 (1996) $1-11$.

[13] H.W. Fan, Y.L. Peng, Z.H. Li, P. Chen, Q. Jiang, S.B. Wang, Preparation and characterization of hydrophobic PVDF membranes by vapor-induced phase separation and application in vacuum membrane distillation, J. Polym. Res. 20 (2013) $1-15$.

[14] C.S. Feng, B.L. Shi, G.M. Li, Y.L. Wu, Preparation and properties of microporous membrane from poly(vinylidene fluoride-co-tetrafluoroethylene) (F2.4) for membrane distillation, J. Membr. Sci. 237 (2004) 15-24.

[15] C. S Feng, R. Wang, B.L. Shi, G.M. Li, Y.L. Wu, Factors affecting pore structure and performance of poly(vinylidene fluoride-co-hexafluoro propylene) asymmetric porous membrane, J. Membr. Sci. 277 (2006) 55-64.

[16] D.L. Wang, K. Li, W.K. Teo, Porous PVDF asymmetric hollow fiber membranes prepared with the use of small molecular additives, J. Membr. Sci. 178 (2000) $13-23$.

[17] M.L. Yeow, Y.T. Liu, K. Li, Preparation of porous PVDF hollow fiber membrane via a phase inversion method using lithium perchlorate $\left(\mathrm{LiClO}_{4}\right)$ as an additive, J. Membr. Sci. 258 (2005) 16-22.

[18] K.Y. Wang, T.S. Chung, M. Gryta, Hydrophobic PVDF hollow fiber membranes with narrow pore size distribution and ultra-thin skin for the fresh water production through membrane distillation, Chem. Eng. Sci. 63 (2008) 25872589.

[19] S. Simone, A. Figoli, A. Criscuoli, M.C. Carnevale, A. Rosselli, E. Drioli, Preparation of hollow fibre membranes from PVDF/PVP blends and their application in VMD, J. Membr. Sci. 364 (2010) 219-232.

[20] M.M. Teoh, T.S. Chung, Membrane distillation with hydrophobic macrovoidfree PVDF-PTFE hollow fiber membranes, Sep. Purif. Technol. 66 (2009) 229236.

[21] M.M. Teoh, N. Peng, T.S. Chung, L.L. Koo, Development of novel multichannel rectangular membranes with grooved outer selective surface for membrane distillation, Ind. Eng. Chem. Res. 50 (2011) 14046-14054.

[22] P. Wang, T.S. Chung, Design and fabrication of lotus-root-like multi-bore hollow fiber membrane for direct contact membrane distillation, J. Membr. Sci. 421-422 (2012) 361-374.

[23] M. Khayet, J.I. Mengual, T. Matsuura, Porous hydrophobic/hydrophilic composite membranes: application in desalination using direct contact membrane distillation, J. Membr. Sci. 252 (2005) 101-113.
[24] M. Khayet, T. Matsuura, M.R. Qtaishat, J.I. Mengual, Porous hydrophobic hydrophilic composite membranes preparation and application in DCMD desalination at higher temperatures, Desalination 199 (2006) 180-181.

[25] M. Qtaishat, D. Rana, M. Khayet, T. Matsuura, Preparation and characterization of novel hydrophobic/hydrophilic polyetherimide composite membranes for desalination by direct contact membrane distillation, J. Membr. Sci. 327 (2009) 264-273.

[26] M. Qtaishata, M. Khayet, T. Matsuura, Novel porous composite hydrophobic hydrophilic polysulfone membranes for desalination by direct contact membrane distillation, J. Membr. Sci. 341 (2009) 139-148.

[27] M. Khayet, C. Cojocaru, M.C. García-Payo, Experimental design and optimization of asymmetric flat-sheet membranes prepared for direct contact membrane distillation, J. Membr. Sci. 351 (2010) 234-245.

[28] M. Essalhi, M. Khayet, Surface segregation of fluorinated modifying macromolecule for hydrophobic/hydrophilic membrane preparation and application in air gap and direct contact membrane distillation, J. Membr. Sci. 417-418 (2012) 163-173.

[29] F. Edwie, T.S. Chung, Development of hollow fiber membranes for water and salt recovery from highly concentrated brine via direct contact membrane distillation and crystallization, J. Membr. Sci. 421-422 (2012) 111-123.

[30] D. Li, R. Wang, T.S. Chung, Fabrication of lab-scale hollow fiber membrane modules with high packing density, Sep. Purif. Technol. 40 (2004) 15-30.

[31] S. Rajesh, K.H. Shobana, S. Anitharaj, D.R. Mohan, Preparation, morphology, performance, and hydrophilicity studies of poly(amide-imide) incorporated cellulose acetate ultrafiltration membranes, Ind. Eng. Chem. Res. 50 (2011) 5550-5564.

[32] K.Y. Wang, S.W. Foo, T.S. Chung, Mixed matrix PVDF hollow fiber membranes with nanoscale pores for desalination through direct contact membrane distillation, Ind. Eng. Chem. Res. 48 (2009) 4474-4483.

[33] K. Ying, Y.L. Wu, J.R. Yang, X. Peng, J.P. Xu, Structural control of microporous PVDF membranes for membrane distillation III. Selection of preparation conditions of membranes and membrane distillation performance, Technol Water Treat. 18 (1992) 167-172.

[34] M. Rafat, D. De, K.C. Khulbe, T. Nguyen, T. Matsuura, Surface characterization of hollow fiber membranes used in artificial kidney, J. Appl. Polym. Sci. 101 (2006) 4386-4400.

[35] J.H. Zhang, N. Dow, M. Duke, E. Ostarcevic, J.D. Li, S. Gray, Identification of material and physical features of membrane distillation membranes for high performance desalination, J. Membr. Sci. 349 (2010) 295-303.

[36] J.H. Zhang, J.D. Li, S. Gray, Effect of applied pressure on performance of PTFE membrane in DCMD, J. Membr. Sci. 369 (2011) 514-525.

[37] M. Essalhi, M. Khayet, Self-sustained webs of polyvinylidene fluoride electrospun nanofibers at different electrospinning times: 1 . Desalination by direct contact membrane distillation, J. Membr. Sci. 433 (2013) 167-179.

[38] C.S. Feng, B.L. Shi, G.M. Li, Y.L. Wu, Preliminary research on microporous membrane from F2.4 for membrane distillation, Sep. Purif. Technol. 39 (2004) 221-228. 